\title{
Sub-optimal Tariff Policy and Gains from Trade for LDCs with Urban Unemployment
}

\author{
M. A LI KHAN and PO-SHENG LIN ${ }^{*}$
}

In this paper we examine the issue of gains from trade in a setting which admits urban unemployment and a variety of urban, labour market conditions. In addition to the conventional criterion, we also consider the case when the size of the urban unemployed is the sole determinant of welfare. The results lean heavily on factor market stability and are sensitive to the commodity being imported and to the assumption of intersectoral mobility of capital.

In the decade since the publication of Harris-Todaro's paper [16], various aspects of the structure of labour markets in LDCs have been formalized and incorporated into a well-articulated, two-sector production model. ${ }^{1}$ Capital has generally been treated as non-shiftable ${ }^{2}$ between the two sectors but recent works have also considered the long run and assumed it to be intersectorally mobile. ${ }^{3}$ However, the primary focus of all of this literature has been on urban wage subsidies and both the positive and the normative aspects of these have been intensively studied. There has been a corresponding neglect of a more traditional question in trade theory; namely, whether economies with such labour market distortions gain from trade? Presumably this neglect is in part due to the following two propositions of Bhagwati $[3 ; 4]$.

1. Growth may be immiserizing for economies with factor market distortions. ${ }^{4}$

*

The authors are Professors in the Department of Political Economy, The Johns Hopkins University, Baltimore, Maryland 21218. They thank T. Datta-Chaudhuri and T. Hatta for encouragement and several helpful suggestions. Responsibility for errors is assumed by the authors alone.

${ }^{1}$ This has also been referred to as the segmentation model of unemployment; see the introduction in Sabot (1978).

${ }^{2}$ It is worth reminding the reader that non-shiftable capital can be alternatively viewed as two different factors, say, rural land and urban capital. On non-shiftable capital, we have, in addition to the work of Harris-Todaro, the investigations of Bhagwati-Srinivasan $[7 ; 8]$, Stiglitz $[34 ; 35 ; 36]$, Corden $[13$, pp. 144-48], Corden-Findlay [14], Srinivasan-Bhagwati [33], Calvo [11], Hazari [17, Chapter 7] and Khan [25].

${ }^{3}$ In the context of intersectoral capital mobility, we have the work of Corden-Findlay [14], Khan [23;24], Neary [29] and Stiglitz [36].

${ }^{4}$ This is just a corollary of Proposition 4 in Bhagwati [3,p. 81] 
2. No-trade and free-trade policies are conceptually the-same as pre-growth and post-growth situations. [As such], the theory of immiserizing growth can be used to illuminate, and prove, other propositions of trade theory where no growth, in an obvious sense, is involved. ${ }^{5}$

We thus seem to have a readily available answer to our question as to whether the policies of free trade and no trade can be ranked uniquely in LDCs suffering from the Harris-Todaro type of distortions. Indeed, one can go further and show that for such economies more restricted trade cannot be ranked uniquely vis-à-vis less restricted trade. This rests on a third proposition of Bhagwati [3] .

3. Reductions in the "degree" of a distortion will not necessarily be welfare-increasing if there is another distortion in the system. ${ }^{6}$

However, reduction of urban unemployment is an important policy objective of LDC governments and the question of gains from trade has typically been studied in models with full employment of labour. ${ }^{7}$ Thus, despite Bhagwati's propositions, it seems desirable to take another look at the gains-from-trade question in the context of a social welfare function with urban unemployment as the sole determinant. We do this in this paper.

Furthermore, we would say that additional analysis is warranted even in the context of traditional social welfare functions. In an earlier paper, one of us showed that growth can never be immiserizing with intersectoral capital mobility and with the various theories of urban wage determination as have been studied in the HarrisTodaro literature; see Khan [26]. Such a result argues for a further scrutiny of the gains-from-trade question in the Harris-Todaro setting. In any case, the question is important enough that it is desirable to have sharper results than can be deduced from Bhagwati's fundamental propositions. To provide such necessary and sufficient conditions is the principal object of this paper. A secondary object is to see what light the assumption of factor market stability sheds on these necessary and sufficient conditions. To our knowledge, such considerations have previously not been brought to bear on the gains-from-trade question. Our results in this regard are more encouraging than the corresponding ones for the wage differential models. ${ }^{8}$

A useful by-product of our investigation is that we obtain formulae for suboptimal or second-best tariffs. These are of relevance to governments which cannot

${ }^{5}$ Bhagwati does not state this as a proposition and these quotes are from Bhagwati $[4, p$.

46]. ${ }^{6}$ This is Proposition 6 in Bhagwati [3,p. 86]. Of course, in our context, the distortion which is being reduced is the tariff rate.

${ }_{7}^{7}$ An exception is the recent work of Brecher [9].

Indeed, in his important paper, Neary [28] dismisses this question in a footnote; see his footnote 8 . intervene in domestic labour markets and which must rely solely on tariff is worth pointing out in this connection that throughout this paper, we confining our attention to a small country which must take the internatio as given. Thus, our sub-optimal tariff formulae are obviously of a differe than the optimal tariff formula for a country with monopoly power in trade

The paper is organized as follows. Section 1 presents the model and lays out the equations which are basic to the subsequent analysis. Section form the core of the paper; the former assumes that capital is intersectoral and the latter that it is non-shiftable. Section 5 is a brief discussion of rela and Section 6 concludes the paper with a summary.

\section{THE GENERALIZED HARRIS-TODARO MODEL}

We shall be working with the generalized Harris-Todaro model which a variety of labour market specifications emphasized in the literature. Such is based on Khan $[24 ; 25]$.

Let a country consist of an urban and a rural sector, indexed by respectively, and let it be endowed with non-negative amounts of labour, capital, $\mathscr{K}$. Let the ith sector produce a commodity in amount $\mathrm{X}_{\mathrm{i}}$ in ace with a production function

$$
\mathrm{X}_{\mathrm{i}}=\mathrm{F}_{\mathrm{i}}\left(\mathrm{L}_{\mathrm{i}}, \mathrm{K}_{\mathrm{i}}\right)
$$$$
\mathrm{i}=\mathrm{u} \text { and } \mathrm{r}
$$

which is assumed to be positively homogeneous of degree 1 , twice cont differentiable and concave. $\mathrm{L}_{\mathrm{i}}$ and $\mathrm{K}_{\mathrm{i}}$ are allocations of labour and capital the mobile capital case, are determined through marginal productivity pric thus have

$$
\begin{aligned}
& P_{r} F_{r}^{K}=R=p_{u} F_{u}^{K} \\
& P_{r} F_{r}^{L}=w_{r} \text { and } p_{u} F_{u}^{L}=w_{u}
\end{aligned}
$$

where $F_{i}^{j}$ is the derivative of $F_{i}$ with respect to $j, j=L, K$ and $i=u, r$. The is too small to influence $\mathrm{p}_{\mathrm{u}}$ and $\mathrm{p}_{\mathrm{r}}$, positive international prices of commodities.

The equilibrium in the labour market is given by

$$
\mathrm{w}_{\mathrm{u}}=(1+\lambda) \mathrm{w}_{\mathrm{r}}
$$

where $\lambda$ is the ratio of the unemployed to the urban employed. Thus $\mathrm{L}_{\mathrm{u}} / \mathrm{L}$

${ }^{9}$ As is well known, the question of sub-optimal tariffs was first raised by Kem [22] and further elaborated upon by Bhagwati-Ramaswami-Srinivasan [6] and Kemp 
can be taken to be the probability of finding a job in the urban sector, a formaliza tion due to Harris-Todaro [16]. Unlike them, however, we shall allow the possibility of the urban wage being endogenously determined. In the mobile capital case this endogeneity is brought out by

$$
\mathrm{w}_{\mathrm{u}}=\Omega\left(\mathrm{w}_{\mathrm{r}}, \lambda, \mathrm{R}, \mathcal{G}\right)
$$

and in the immobile capital case by

$$
\mathrm{w}_{\mathrm{u}}=\Omega\left(\mathrm{w}_{\mathrm{e}}, \lambda, \mathrm{K}_{\mathrm{u}}, \mathcal{T}\right)
$$

where $\mathscr{T}$ is a shift parameter. For a discussion of the microfoundations of $(1.4 \mathrm{a}$ and $1.4 \mathrm{~b}$ ), see Khan [25 and 26 respectively]. There it is shown that specializations of the $\Omega(\cdot)$ functions yield not only the original Harris-Todaro rigid wage setting studied further by Bhagwati-Srinivasan, Corden-Findlay, Stiglitz ${ }^{10}$ and others, but also allow us to incorporate considerations arising from labour-turnover as in Akerlof-Stiglitz [1], and Stiglitz [34], or the efficiency wage as in Stiglitz [35], or the presence of trade-unions as in Calvo [11], or from costly supervision as in Calvo-Wellisz - see Calvo [10]. ${ }^{11}$

Addition of the following two equations completes the specification of the model in the mobile capital case.

$$
\mathrm{K}_{\mathrm{r}}+\mathrm{K}_{\mathrm{u}}=\mathscr{K} \text { and } \mathrm{L}_{\mathrm{r}}+\mathrm{L}_{\mathrm{u}}(1+\lambda)=\mathscr{L}
$$

For the immobile capital case, the first equation in (1.5) has no meaning.

\section{PRELIMINARY ANALYSIS OF THE PROBLEM}

The following classical propositions relate to the commercial policies and questions we shall pursue in the sequel.

(1) Superiority of free trade to autarchy; Samuelson [31].

(2) Optimality of free trade for a country with no monopoly power in trade; Samuelson [31].

(3) Desirability of terms-of-trade improvement; Krueger-Sonnenschein [27].

(4) Superiority of less restricted trade over more restricted trade; Kemp [21], and Bhagwati and Kemp [5].

${ }^{10}$ The reference to Stiglitz is his forthcoming piece in the Sabot volume [30]. For the vork of the other authors, see the references listed in footnotes 3 and 4 .

${ }^{11}$ By rewriting $(1.3)$ as $w_{u}=\tau\left(w_{r}\right)(1+\lambda) w_{r}$ where $\tau(\cdot)$ a shift function, the model also yields the traditional absolute or proportional wage-differential models as a special case. We shall not pursue this here.
(5) Existence of an optimal tariff in the presence of domestic distortions; Kemp and Negishi [22], and Bhagwati-Ramaswami-Srinivasan [6].

We shall be analyzing these commercial policies in terms of two welfare functions. The first is simply

$$
\mathrm{W}=\phi\left(\lambda \mathrm{L}_{\mathrm{u}}\right), \phi^{\prime}(\cdot)<0
$$

The second is the more traditional

$$
\mathrm{U}=\mathrm{U}\left(\mathrm{C}_{\mathrm{r}} \cdot \mathrm{C}_{\mathrm{u}}\right)
$$

where $\mathrm{C}_{\mathrm{i}}$ is the domestic consumption of commodity $\mathrm{i}$. In the remainder of this section, we shall show that an analysis of the social welfare function, $U$, also reduces to the analysis of changes in the rate of urban unemployment, $\lambda$.

This can be seen most simply by working with the minumum expenditure function rather than with $U(\cdot)$. Let $g\left(p_{r}, p_{u}, U\right)$ be the minimum expenditure at the prices $p_{r}, p_{u}$ required to attain the level of social welfare given by $U$. It is well known (see, for example, the expository paper of Gorman [15]), that $g$ is (i) positively homogeneous of degree one in prices; (ii) concave function of the prices; and (iii) such that $\mathrm{g}_{\mathrm{i}} \equiv \partial \mathrm{g}(\cdot) / \partial \mathrm{p}_{\mathrm{i}}=\mathrm{C}_{\mathrm{i}}$, i $=\mathrm{u}$, r. Now let $\mathrm{u}$ be the imported commodity and $t$ the tariff rate. Then the following equation is basic for the analysis of tariff policy of a "small" economy.

$$
g\left(p_{r}, p_{u}(1+t), U\right)=p_{r} X_{r}+p_{u}(1+t) X_{u}+p_{u}^{t}\left(g_{u}-X_{u}\right)
$$

Equation (2.2) represents the national expenditure/national income identity with the third term on the right hand side obviously being the tariff revenue. Differentiating (2.2) with respect to $t$ and noting that

$$
\frac{\partial}{\partial t}\left(p_{r} X_{r}+p_{u}(1+t) X_{u}\right)=-w_{r} L_{u} \frac{\partial \lambda}{\partial t}+p_{u} X_{u}
$$

we obtain

$$
g_{0}\left(1-\frac{m t}{1+t}\right) \frac{\partial U}{\partial t}=\left(p_{u}^{2} t\right)\left\{g_{u u}-\frac{\partial X_{u}}{\partial p_{u}(1+t)}\right\}-w_{r} L_{u} \frac{\partial \lambda}{\partial t}
$$

where $g_{0}$ is the inverse of the marginal utility of income and $\mathrm{m}$ is the marginal propensity to consume the imported commodity.

It is well known that positivity of the term $(1-(\mathrm{mt} / 1+\mathrm{t}))$ is precisely the condition for international commodity markets to be stable when the terms of trade are given; see Kemp [21] and Bhagwati and Kemp [5]. We shall assume this to be so in 
the sequel. Thus, the analysis of the propositions listed above reduces to evaluation of the sign of the term $\partial \mathrm{U} / \partial \mathrm{t}$. Given concavity assumptions, ${ }^{12}$ the substitution term is negative and we are reduced to an analysis of the price-output response $\partial X_{u} / \partial p_{u}$ $(1+t)$ and the unemployment rate response $\partial \lambda / \partial t$. However, if we denote the compensated (constant utility) price elasticity of urban imports by $\epsilon_{u}$, equation (2.4) can be manipulated to yield ${ }^{13}$

$$
\mathrm{g}_{\mathrm{o}}\left(1-\frac{\mathrm{mt}}{1+\mathrm{t}}\right) \frac{\mathrm{dU}}{\mathrm{dt}}=\mathrm{p}_{\mathrm{u}} \mathrm{X}_{\mathrm{u}}\left[\frac{\mathrm{t}\left(\mathrm{C}_{\mathrm{u}}-\mathrm{X}_{\mathrm{u}}\right)}{(1+\mathrm{t}) \mathrm{X}_{\mathrm{u}}} \in_{\mathrm{u}}-\theta_{\mathrm{uL}} \frac{\hat{\lambda}}{\hat{\mathrm{t}}}\right]
$$

Thus, an increase in the tariff rate on urban imports leads to an increase in welfare if and only if

$$
(\mathrm{t} / 1+\mathrm{t})\left(\left(\mathrm{C}_{\mathrm{u}}-\mathrm{X}_{\mathrm{u}}\right) / \mathrm{X}_{\mathrm{u}}\right) \in_{\mathrm{u}}>\theta_{\mathrm{uL}}(\hat{\mathrm{\lambda}} / \hat{\mathrm{t}})
$$

Unlike the HOS setting, the asymmetric role of the urban and rural sectors calls for a modification of (2.6) when the rural commodity is being imported. ${ }^{14}$ The reader can check for himself that an increase in the tariff rate on rural imports leads to an increase in welfare if and only if

$$
(\mathrm{t} / 1+\mathrm{t})\left(\left(\mathrm{C}_{\mathrm{r}}-\mathrm{X}_{\mathrm{r}}\right) / \mathrm{X}_{\mathrm{r}}\right) \in_{\mathrm{r}}>\theta_{\mathrm{rL}}\left(\left(\mathscr{L}-\mathrm{L}_{\mathrm{r}}\right) / \mathrm{L}_{\mathrm{r}}\right)(\hat{\lambda} / \hat{\mathrm{t}})
$$

Analysis of terms-of-trade changes involves no tariffs and in this case, the analogue of $(2.4)$ is

$$
\mathrm{g}_{\mathrm{o}} \frac{\partial \mathrm{U}}{\partial \mathrm{p}_{\mathrm{i}}}=-\left(\mathrm{C}_{\mathrm{i}}-\mathrm{X}_{\mathrm{i}}\right)-\mathrm{w}_{\mathrm{r}} \mathrm{L}_{\mathrm{u}} \frac{\partial \lambda}{\partial \mathrm{p}_{\mathrm{i}}} \quad(\mathrm{i}=\mathrm{u}, \mathrm{r})
$$

Thus, an improvement in the terms of trade leads to an improvement in welfare if and only if

$$
\begin{aligned}
& \left(\hat{\lambda} / \hat{p}_{\mathrm{u}}\right)>-\left(\left(\mathrm{C}_{\mathrm{u}}-\mathrm{X}_{\mathrm{u}}\right) / \mathrm{X}_{\mathrm{u}}\right)\left(1 / \theta_{\mathrm{uL}}\right) \\
& \left(\hat{\lambda} / \hat{\mathrm{p}}_{\mathrm{r}}\right)>-\left(\left(\mathrm{C}_{\mathrm{r}}-\mathrm{X}_{\mathrm{r}}\right) / \mathrm{X}_{\mathrm{r}}\right)\left(\mathrm{L}_{\mathrm{r}} / \mathscr{L}-\mathrm{L}_{\mathrm{r}}\right)\left(1 / \theta_{\mathrm{rL}}\right)
\end{aligned}
$$

${ }^{12}$ The reader should be reminded that a strictly concave function does not imply that its second derivative is negative everywhere. We shall ignore this pathological possibility here.

${ }^{13}$ Henceforth $\hat{x}$ denotes $d x / x$ except for $\hat{\lambda}$ and $\hat{t}_{i}$ which are respectively given by $d \lambda /(1+\lambda)$ and $\mathrm{dt}_{\mathrm{i}} / 1+\mathrm{t}_{\mathrm{i}}$. This latter modification is required to admit cases when $\lambda$ or $t_{i}$ may be zero. Furthermore, $\theta_{i L}$ is the share of labour in the ith sector, $i=u, r$.

${ }^{14} \mathrm{This}$ is of course not in contrast to the differential wage models, see Batra [2, pp. $263-70]$.

\section{THE SETTING WITH INTERSECTORALLY MOBILE CAPITAL}

In this section we present results on gains from trade when capital is intersectorally mobile. These results are developed in three steps. Firstly, we consider the effect of tariffs and terms of trade changes on urban employment. Secondly, we recall a result on a characterization of dynamic stability in factor markets. Finally, we piece these steps together in terms of the analysis presented in Section 2. The results on the effects of tariffs on urban employment may be of independent interest.

\subsection{The Effect of a Tariff on Urban Employment}

One of the points emerging from Khan [24], is that the generalized HarrisTodaro model with capital mobility shares the essential properties of the HeckscherOhlin-Samuelson (HOS) model. It is well known that in such a model, the effect of a tariff on wages and rents depends on factor intensities, i.e., on

(3.1.1) Sign $\left[\theta_{\mathrm{uK}} \theta_{\mathrm{rL}}-\theta_{\mathrm{rK}} \theta_{\mathrm{uL}}\right]$

where $\theta_{\mathrm{ij}}$ is the share of the $\mathrm{jth}$ factor in the value of ith sector output. Now, given the labour market equilibrium condition

(3.1.2) $\quad \mathrm{w}_{\mathrm{r}}(1+\lambda)=\Omega\left(\mathrm{w}_{\mathrm{r}}, \lambda, \mathrm{R}, \mathscr{F}\right)$

in the Harris-Todaro model, the effect of tariffs on the unemployment rate $\lambda$ reduces to the effects of tariffs on rural wages and rentals. Exploiting the resemblance to the HOS model, such effects also depend on factor intensity conditions provided these are suitably interpreted. We turn to this.

$\theta_{\mathrm{ij}}$ can be alternatively and more usefully viewed as the proportional change in the cost of production of the ith commodity for a cet. par. proportional change in the price of the jth factor. Thus all we need to do in our generalized setting is to calculate such changes in the various costs of production by allowing for the fact that $w_{u}$ is not being changed directly but as a result of changes in $w_{r}, R$ and $\lambda$. Thus, $\theta_{\mathrm{rK}}$ and $\theta_{\mathrm{rL}}$ need no modification but $\theta_{\mathrm{uL}}$ and $\theta_{\mathrm{uK}}$ need to be recalculated. Let the elasticities corresponding to the $\Omega(\cdot)$ function be given by

$$
\mathrm{e}_{\mathrm{w}}=\frac{\partial \log \Omega(\cdot)}{\partial \log \mathrm{w}_{\mathrm{r}}}, \mathrm{e}_{\lambda}=\frac{\partial \log \Omega(\cdot)}{\partial \lambda}, \mathrm{e}_{\mathrm{R}}=\frac{\partial \log \Omega(\cdot)}{\partial \log \mathrm{R}}
$$

and consider a cet. par. proportional change in the rural wage. This has two effects on the cost of production of the uth commodity. A direct effect resulting from a 
change in the urban wage and a consequent change in costs, i.e., $\theta_{u L^{e}}{ }_{w}$; and an indirect effect arising from the adjustment in $\lambda$ required to maintain the equilibrium condition (3.1.2). This adjustment in $\lambda$ is given by

(3.1.3) $\quad \hat{\lambda} / \hat{w}_{\mathrm{r}}=\left(1-\mathrm{e}_{\mathrm{w}}\right) /\left(\mathrm{e}_{\lambda}-1\right)$

and causes corresponding changes in the urban wage and urban costs of production. Putting these two effects together, we obtain the recalculated $\theta_{u L}$, henceforth $\theta_{u L}^{\prime}$, to be

(3.1.4) $\theta_{u L} e_{w}+\frac{\theta_{u L} e_{\lambda}\left(1-e_{w}\right)}{e_{\lambda}-1}=\frac{\theta_{u L}}{e_{\lambda}-1}\left(e_{\lambda}-e_{w}\right)$

Analogous reasoning yields a recalculated $\theta_{\mathrm{uK}}$. Here, in addition to the direct effect $\theta_{\mathrm{uK}}$, there are two indirect effects. Both of these involve induced changes in the urban wage; the first is the direct change $e_{R}$ and the second stems from the adjustment in $\lambda$ required to maintain (3.1.2), i.e., $e_{R} /\left(e_{\lambda}-1\right)$. Putting all of these together, we obtain,

$$
\theta_{u K}^{\prime}=\theta_{u K}+e_{R} \theta_{u L}-\frac{\theta_{u L} e_{\lambda} e_{R}}{e_{\lambda}-1}=\frac{\left[\theta_{u K}\left(1-e_{\lambda}\right)+\theta_{u L} e_{R}\right]}{1-e_{\lambda}}
$$

We can now obtain the correct analogue of (3.1.1) in the Harris-Todaro set-up. This is given by

(3.1.6a) $\operatorname{Sign}|\Delta|=\operatorname{Sign}\left[\theta_{\mathrm{uK}}^{\prime} \theta_{\mathrm{rL}}-\theta_{\mathrm{uL}}^{\prime} \theta_{\mathrm{rK}}\right]$

$$
=\operatorname{Sign}\left[\theta_{\mathrm{rL}}\left\{\theta_{\mathrm{uK}}\left(1-\mathrm{e}_{\lambda}\right)+\theta_{\mathrm{uL}} \mathrm{e}_{\mathrm{R}}\right\}+\theta_{\mathrm{rK}}\left[\theta_{\mathrm{uL}}\left(\mathrm{e}_{\lambda}-\mathrm{e}_{\mathrm{w}}\right)\right\}\right]
$$

So far we have been considering changes in the unemployment rate and hence focussed on the Stolper-Samuelson property of the model. As an inspection of (2.4) makes clear, we also need to consider the price-output responses. Again, drawing on the analogy with the HOS model, or rather its varient as in Jones [18], we need analogues of physical factor intensities in addition to the value intensities of (3.1.1). These are straightforward. Our model exhibits a version of the Rybczynski property $^{15}$ in that the factor intensity pertaining to the urban sector has to be calculated inclusive of the unemployed labour force. Thus, the effect on outputs of cet. par. changes in factor endowments depend on the sign of

$$
\left(\mathrm{K}_{\mathrm{u}} / \mathrm{L}_{\mathrm{u}}(1+\lambda)\right)-\left(\mathrm{K}_{\mathrm{r}} / \mathrm{L}_{\mathrm{r}}\right) \equiv\left(\frac{\mathrm{k}_{\mathrm{u}}}{1+\lambda}-\mathrm{k}_{\mathrm{r}}\right)
$$

${ }^{15}$ See Khan [24]. or with slight rewriting on

$$
\text { (3.1.8) Sign }|\mathrm{D}|=\theta_{\mathrm{uK}} \theta_{\mathrm{rL}}-\theta_{\mathrm{rK}} \theta_{\mathrm{uL}}
$$

Thus, the price output response depends on Sign ( $|D| x|\Delta|)$ just as in Jones [18]

(3.1.6) and (3.1.8) represent the two basic elements of the model. Using them, we can derive ${ }^{16}$ the following relationships

(3.1.9a) $\quad \dot{\lambda} / \hat{\mathrm{t}}_{\mathrm{u}}=\left(1+\left(\mathrm{e}_{\lambda}-1\right) \frac{|\mathrm{D}|}{|\Delta|}\right) / \theta_{\mathrm{uL}}=\left(\theta_{\mathrm{rK}}\left(1-\mathrm{e}_{\mathrm{w}}\right)+\theta_{\mathrm{rL}} \mathrm{e}_{\mathrm{R}}\right) /|\Delta|$

(3.1.9b) $\dot{\lambda} / \hat{\mathrm{t}}_{\mathrm{r}}=\left(\left(\mathrm{e}_{\mathrm{w}}-\mathrm{e}_{\lambda}\right) \frac{|\mathrm{D}|}{|\Delta|}-1\right) / \theta_{\mathrm{rL}}=-\left(\theta_{\mathrm{rL}}\left(1-\mathrm{e}_{\mathrm{w}}\right)+\right.$

$$
\left.\theta_{u L} e_{R}\right) /|\Delta|
$$

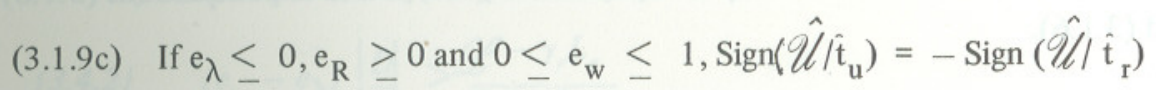

$$
=\operatorname{Sign}(|D| \times|\Delta|)
$$

where $\mathscr{U}$ is the size of the urban unemployed. Two final remarks. There is an implicit assumption in these formulae that when changes in $t_{i}$ are being considered, the ith commodity is being imported and that $t_{j}$ is zero. Secondly, it is obvious that formulae (3.1.9) remain the same when changes in $p_{i}$ rather than $t_{i}$ are being considered.

\subsection{A result on Dynamic Stability in Factor Markets}

In this section we recall a result on the characterization of dynamic stability in factor markets. The underlying adjustment process $\mathscr{P}^{6}$ is defined by the following differential equations.

$$
\begin{array}{ll}
\mathscr{D} \mathrm{K}_{\mathrm{r}}=\phi\left\{\left(\mathrm{R}_{\mathrm{r}} / \mathrm{R}_{\mathrm{u}}\right)-1\right\} & \phi^{\prime}>0, \phi(0)=0 \\
\left.\mathscr{D} \mathrm{L}_{\mathrm{r}}=\psi\left\{\mathrm{w}_{\mathrm{r}}(1+\lambda) / \mathrm{w}_{\mathrm{u}}\right)-1\right\} & \psi^{\prime}>0, \psi(0)=0 \\
\mathscr{D} \lambda=\pi\left\{\left(\Omega(\cdot) / \mathrm{w}_{\mathrm{u}}\right)-1\right\} & \pi^{\prime}>0, \pi(0)=0
\end{array}
$$

where $\mathscr{D}$ is the time derivative operator and $\mathrm{R}_{\mathrm{i}}$ is the rural in sector $\mathrm{i}, \mathrm{i}=\mathrm{u}, \mathrm{r}$.

${ }^{16}$ For equations (3.1.9a and b), see equation 2.9 in Khan [23]. Equations (3.1.9c) follow from equations (3.3.1) in Khan [23]. Indeed, Sections 2 and 3 in Khan [23] can be seen as a mathematical appendix to Section 3.1 of this paper. 
Such a process has been discussed by Khan [23] and he has shown ${ }^{17}$

Theorem 3.2.1. Let $|D| \neq 0,|\Delta| \neq 0$ at a particular equilibrium. Then local asymptotic stability of such an equilibrium implies that

$$
\operatorname{Sign}(|D| x|\Delta|)>0
$$

Such a result is very much in the same spirit as Neary's [28] result on the characterization of factor market stability in differential wage models. There he has shown that stability of equilibrium of a particular adjustment process is equivalent to the requirement that physical factor intensities coincide with value intensities in their ranking of the two sectors. In keeping with our emphasis on the resemblance of our model to the HOS model, we obtain a similar result provided we work with employment adjusted and elasticities adjusted intensities, i.e., D and $\Delta$ of equations (3.1.8) and (3.1.6).

\subsection{Results on Gains from Trade in Terms of W}

We are now ready to address the question of gains from trade when the size of the urban unemployed is the sole determinant of welfare. As (3.1.9c) makes clear, the answer revolves around stability in factor markets. Indeed we can state

PROPOSITION 3.3.1. Let factor markets be dynamically stable in terms of adjustment process $\mathscr{P}^{\circ}$, and let $e_{\lambda} \leq 0, e_{R} \geq 0,0 \leq e_{w} \leq 1$. Then

(a) If the urban commodity is being imported, free trade is the optimal policy; improvement in the terms of trade improve welfare; less-restricted trade is superior to more-restricted trade and $t_{u}^{*}=0$ is the optimal tariff.

(b) If the rural commodity is being imported; free trade is the worst policy; improvement in the terms of trade cause a deterioration in welfare; morerestricted trade is superior to less-restricted trade and the second best tariff is the prohibitive tariff which guarantees autarchy.

A final remark. The word optimal is being used in a second best sense and specifically with regard to the policy being considered, i.e., a tariff on imports. In deed, if subsidies are allowed, then imports of the urban commodity should be subsidized.

${ }^{17}$ This is half of Theorem 5.1 in Khan [23]. There, he has shown that $(|\mathrm{D}| \mathrm{x}|\Delta|)>0$ is necessary and sufficient for dynamic stability under conditions on the elasticities $e_{w}, e_{R}$ and e $\lambda$. It is easy to check that the proof of Theorem 3.2.1 is independent of these elasticities.

\subsection{Results on Gains from Trade in Terms of $U$}

We now consider the case when social welfare is a concave function of domestic consumption. Our first result pertains to changes in the terms of trade. Let $\gamma_{i}$ be the ratio of domestic consumption to domestic production of commodity $i$. Then (2.9) and (3.1.9) yield

\section{PROPOSITION 3.4.1}

(a) Let the urban commodity be imported. Then improvements in the terms of trade improve welfare if and only if

(3.4.1) $\left(1-e_{\lambda}\right) \frac{|D|}{|\Delta|}<\gamma_{u}$

(b) Let the rural commodity be imported. Then improvements in the terms of trade improve welfare if and only if

(3.4.2) $\quad\left(e_{w}-e_{\lambda}\right) \mid \frac{|D|}{|\Delta|}>\frac{\mathscr{L}-\gamma_{r} L_{r}}{\mathscr{L}-L_{r}}$

Remark 3.4.1. If $\mathrm{e}_{\lambda} \leq 0, \mathrm{e}_{\mathrm{w}} \geq 0$, but not both zero, and $\ell_{\mathrm{r}} \gamma_{\mathrm{r}} \equiv\left(\mathrm{L}_{\mathrm{r}} / \mathscr{L}\right) \gamma_{\mathrm{r}} \leq 1$, then unstable factor markets imply that terms of trade never improve welfare if the rural commodity is being imported.

Remark 3.4.2. For the rigid wage setting studied by Corden and Findlay [14], Stiglitz [36] and others, $e_{w}=e_{\lambda}=0$, and Remark 3.4.1 can be sharpened to say that with rural imports, improvements in the terms of trade improve welfare if and only if $\ell_{r} \gamma_{r}>1$. With urban imports, the relevant condition is

$$
\mathrm{k}_{\mathrm{u}}\left(1-\gamma_{\mathrm{u}}\right)<(1+\lambda) \mathrm{k}_{\mathrm{r}}
$$

This is always fulfilled. Indeed, we can go beyond the rigid wage setting to say that with $\mathrm{e}_{\lambda}=0$, with the urban commodity being imported, improvements in the terms of trade always cause an improvement in welfare.

Remark 3.4.3. If $\mathrm{e}_{\mathrm{w}}=1$ and $\mathrm{e}_{\mathrm{R}}=0$ as in the HOS model or as in the trade union setting of Calvo [11], (3.4.1) and (3.4.2) respectively reduce to the requirement that $\gamma_{u}$ and $\gamma_{r}$ exceed unity. This is always fulfilled.

We now consider the desirability of tariffs when the economy is initially in a laissez-faire equilibrium. Then (2.4) reduces to

$$
\operatorname{Sign}(\partial U / \partial t)=-\operatorname{Sign}(\hat{\lambda} / \hat{t})
$$

and equations (3.1.9) yield 
PROPOSITION 3.4.2. Let the economy be initially in a laissez-faire equilibrium. (a) If the urban commodity is being imported, then there exists a welfare-improving tariff if and only if

$$
\left(1-e_{\lambda}\right)(|D| /|\Delta|)>1
$$

or, equivalently, if and only if

$$
\left(\theta_{r K}\left(1-e_{w}\right)+\theta_{r L} e_{R}\right) /|\Delta|<0
$$

(b) If the rural commodity is being imported, then there exists a welfareimproving tariff if and only if

$$
\left(e_{w}-e_{\lambda}\right)(|D| /|\Delta|)<1
$$

or, equivalently, if and only if

$$
\left(\theta_{u K}\left(1-e_{w}\right)+\theta_{u L} e_{R}\right) /|\Delta|>0
$$

Remark 3.4.4. If $\mathrm{e}_{\lambda} \leq 0$, then unstable factor markets imply that there does not exist a welfare improving tariff on urban imports.

Remark 3.4.5. If $\mathrm{e}_{\mathrm{w}}=1$ and $\mathrm{e}_{\mathrm{R}}=0$ as in the Heckscher-Ohlin-Samuelson model or as in the trade union setting studied by Calvo [11], there does not exist a welfare-improving tariff.

Remark 3.4.6. Let $\mathrm{e}_{\mathrm{R}} \geq 0$ and $0 \leq \mathrm{e}_{\mathrm{w}}<1$. Then, there exists a welfare-improving tariff on urban imports if and only if the urban sector is labour intensive in elasticities adjusted terms, i.e., $\Delta<0$; and on rural imports if and only if the urban sector is capital intensive in elasticities adjusted terms, i.e., $\Delta>0$.

Remark 3.4.7. In the rigid-wage setting, $\mathrm{e}_{\mathrm{R}}=\mathrm{e}_{\mathrm{w}}=0$ and hence there always exists a welfare-improving tariff on rural imports and never on urban imports.

Our final result of this subsection concerns sub-optimal tariffs and the superiority of less-restricted trade to more-restricted trade. Equations (2.6), (2.7) and (3.1.9) yield

PROPOSITION 3.4.3. Less-restricted trade is superior (inferior) to more-restricted trade if and only if in the neighbourhood of $t_{i}^{*}, t_{i}>t_{i}^{*}\left(t_{i}<t_{i}^{*}\right)$ where the sub-optimal tariffs $t_{i}^{*}$ are given by
(3.4.3) $\frac{t_{u}^{*}}{1+t_{u}^{*}}=\left(\frac{1}{\gamma_{u}-1}\right)\left(\frac{1}{\epsilon_{u}}\right) \frac{\theta_{u L}\left(\theta_{r K}\left(1-e_{w}\right)+\theta_{r L} e_{R}\right)}{|\Delta|}$

(3.4.4) $\frac{t_{r}^{*}}{1+t_{r}^{*}}=-\left(\frac{1}{\gamma_{r}-1}\right)\left(\frac{1}{\epsilon_{r}}\right) \frac{\ell_{u}(1+\lambda)}{\ell_{r}} \frac{\theta_{r L}\left(\theta_{u K}\left(1-e_{w}\right)+\theta_{u L} e_{R}\right)}{|\Delta|}$

Remark 3.4.8. If $\mathrm{e}_{\mathrm{w}}=1$ and $\mathrm{e}_{\mathrm{R}}=0, \mathrm{t}_{\mathrm{u}}^{*}=\mathrm{t}_{\mathrm{r}}^{*}=0$, and less-restricted trade is always superior to more-restricted trade. This is an alternative statement of Remark 3.4.5.

Remark 3.4.9. Let $0 \leq \mathrm{e}_{\mathrm{w}}<1$ and $\mathrm{e}_{\mathrm{R}} \geq 0$. Then the urban sector being more capital intensive in elasticity-adjusted terms than the rural sector implies that

$$
\mathrm{t}_{\mathrm{u}}^{*}<0 \text { and } \mathrm{t}_{\mathrm{r}}^{*}>0
$$

and vice versa if the urban sector is more labour intensive.

Remark 3.4.10. It is worth emphasizing that equations (3.4.3) and (3.4.4) characterize the sub-optimal tariffs if they exist; we offer no sufficient conditions which guarantee their existence, much less their uniqueness. ${ }^{18}$ It is because of this lack of uniqueness that we only confine ourselves to tariffchanges in the neighbourhood of the optimal ones.

\section{THE SETTING WITH INTERSECTORALLY IMMOBILE CAPITAL}

In this section we reconsider the results of Section 3 in the context of immobile capital. The organization of this section is identical to that of Section 3. It is worth mentioning, however, that dynamic stability conditions do not play as prominent a role.

\subsection{The Effect of a Tariff on Urban Unemployment}

We begin this subsection with the observation that the generalized HarrisTodaro model with immobile capital shares essential properties of the RicardoViner model. ${ }^{19}$ It is well known ${ }^{20}$ that the analysis of such a model reduces to

${ }^{18}$ Such conditions would involve determination of the second derivatives of $\Omega(\cdot)$ and third derivatives of $\mathrm{F}_{\mathrm{i}}(\bullet)$.

${ }^{19}$ See Chapter 6 in Caves and Jones [12] and Jones [19] and the references therein.

${ }^{20}$ See Jones [19]. 
studying the equation system

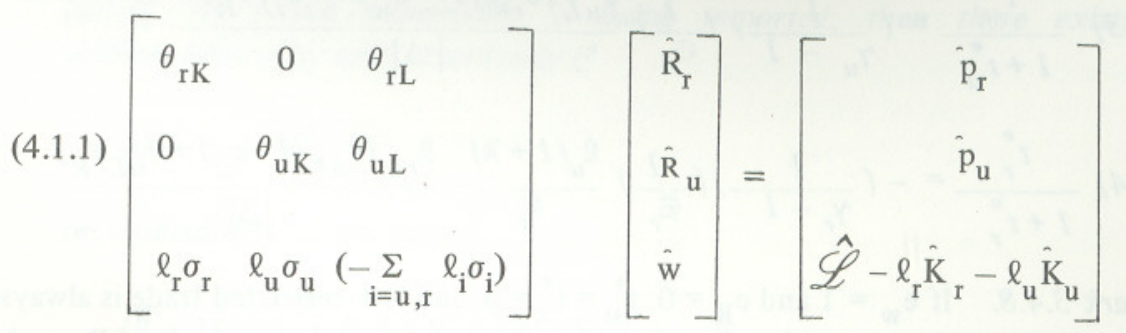

where $\sigma_{i}$ is the elasticity of substitution in sector $i$ and $\ell_{i}=L_{i} / \mathscr{L}$. Just as in Section 3 , a corresponding equation system for the Harris-Todaro setting can be written down by suitable recalculations of the $\theta_{\mathrm{ij}}$ and $\sigma_{\mathrm{i}}$. Now, if we choose to work with the rural wage $\hat{w}_{\mathrm{r}}$ as the relevant unknown, $\theta_{\mathrm{rK}}$ and $\theta_{\mathrm{rL}}$ remain the same. Since $\hat{\mathrm{R}}_{\mathrm{u}}$ does not enter in $\Omega(\cdot)$ function (see $2.4 \mathrm{~b}$ ), $\theta_{\mathrm{uK}}$ is also unchanged. Thus the only recalculation pertains to $\theta_{\mathrm{uL}}$ which can be now written as

$$
\theta_{u L}\left(e_{\lambda}-e_{w}\right) /\left(e_{\lambda}-1\right)
$$

as discussed under (3.1.4). In the third row of the matrix in (4.1.1), the only changes are that $\ell_{u}$ is measured inclusive of urban unemployment, i.e., $L_{u}$ $(1+\lambda) / \mathscr{L}$ and that $-\Sigma \ell_{\mathfrak{i}} \sigma_{\mathfrak{i}}$, the aggregate elasticity of labour demand, is given by (4.1.3) $-\ell_{r} \sigma_{r}-\frac{\ell_{u} \sigma_{u}\left(e_{\lambda}-e_{w}\right)}{e_{\lambda}-1}+\frac{\ell_{u}\left(1-e_{w}\right)}{e_{\lambda}-1}$

The first term needs no explanation. $\ell_{u} \sigma_{u}$ is the cet. par. change in the demand for urban labour when the urban wage changes and it has to be corrected for the fact that we are considering rural wage changes. The correction is the same as the one in (4.1.2) or (3.1.4). The last term pertains to $\hat{\lambda} / \hat{w}_{r}$, i.e., the change in the unemployment rate and this has also been discussed earlier under (3.1.3).

We can now calculate changes in $R_{i}$ and $w_{r}$, and hence $\lambda$, for corresponding changes in $\mathrm{p}_{\mathrm{i}}$. However, at this point a natural question arises as to why we do not exploit this resemblance with the Ricardo-Viner model even further and merely substitute the modified entries (4.1.2) and (4.1.3) in the solutions calculated, say, by Jones [19]. The reason is that these solutions for the Ricardo-Viner model crucially rely on the fact that the first two rows of the matrix sum to unity and the last sums to zero. Our reformulated matrix loses both of these properties.

By routine calculations, we can accordingly derive ${ }^{21}$

(4.1.4a) $\quad \hat{\lambda} / \hat{\mathrm{t}}_{\mathrm{i}}=\ell_{\mathrm{i}} \eta_{\mathrm{i}}\left(1-\mathrm{e}_{\mathrm{w}}\right) / \Delta$

$$
(\mathrm{i}=\mathrm{u}, \mathrm{r})
$$

${ }^{21}$ These routine calculations are available on request. The reader should note, however, that we abuse notation by using $\Delta$ for two different expressions. No confusion should result. (4.1.4b) $\mathrm{L}_{\mathrm{u}} / \hat{\mathrm{t}}_{\mathrm{u}}=\eta_{\mathrm{u}}\left(\ell_{\mathrm{u}}\left(1-\mathrm{e}_{\mathrm{w}}\right)-\ell_{\mathrm{r}} \eta_{\mathrm{r}}\left(1-\mathrm{e}_{\lambda}\right)\right) / \Delta$

(4.1.4c) $\quad \hat{\mathrm{L}}_{\mathrm{u}} / \hat{\mathrm{t}}_{\mathrm{r}}=\eta_{\mathrm{u}} \eta_{\mathrm{r}} \ell_{\mathrm{r}}\left(\mathrm{e}_{\lambda}-\mathrm{e}_{\mathrm{w}}\right) / \Delta$

(4.1.4d) $\Delta=\left(1-\mathrm{e}_{\mathrm{w}}\right) \ell_{\mathrm{u}}-\ell_{\mathrm{r}} \eta_{\mathrm{r}}\left(1-\mathrm{e}_{\lambda}\right)-\ell_{\mathrm{u}} \eta_{\mathrm{u}}\left(\mathrm{e}_{\mathrm{w}}-\mathrm{e}_{\lambda}\right)$

where $\eta_{i}$ is the elasticity of demand ${ }^{22}$ for labour in sector $i$.

The size of the urban unemployed is given by $\mathscr{U}=\lambda L_{u}$ and thus we can write

(4.1.5a) $\hat{\mathscr{U}} / \hat{\mathrm{t}}_{\mathrm{u}}=\ell_{\mathrm{r}} \eta_{\mathrm{r}} \eta_{\mathrm{u}}\left(1-\mathrm{e}_{\lambda}\right) / \Delta$

(4.1.5b) $\hat{\mathscr{U}} / \hat{\mathrm{t}}_{\mathrm{r}}=\left\{\ell_{\mathrm{r}} \eta_{\mathrm{r}}\left(1-\mathrm{e}_{\mathrm{w}}\right)+\ell_{\mathrm{r}} \eta_{\mathrm{r}} \eta_{\mathrm{u}}\left(\mathrm{e}_{\lambda}-\mathrm{e}_{\mathrm{w}}\right)\right\} / \Delta$

4.2 A Result on Dynamic Stability in Factor Markets

Consider an adjustment process $\mathscr{R}$ defined by the following differential equations.

$$
\begin{array}{ll}
\mathscr{D} \mathrm{w}_{\mathrm{r}}=\phi\left\{\left(\mathrm{L}_{\mathrm{r}}+(1+\lambda) \mathrm{L}_{\mathrm{u}} / \mathscr{L}\right)-1\right\} & \phi^{\prime}(0)>0, \phi(0)=0 \\
\mathscr{D} \lambda=\psi\left\{\left(\Omega(\cdot) /(1+\lambda) \mathrm{w}_{\mathrm{r}}\right)-1\right\} & \psi^{\prime}(0)>0, \psi(0)=0
\end{array}
$$

Khan [26] has shown ${ }^{23}$

Theorem 4.2.1. Let $e_{\lambda}<1$ at a particular equilibrium. Then local asymptotic stability of such an equilibrium implies that $\Delta>0$.

It is worth emphasizing that it is not true that asymptotic stability of a particular equilibrium in terms of the adjustment process $\mathscr{R}$ implies that $\mathrm{e}_{\mathrm{w}} \leq 1$.

\subsection{Results on Gains from Trade in Terms of $W$}

We are now ready to address the question of gains from trade. We shall assume throughout this subsection that the following hypothesis is satisfied at equilibrium.

Assumption $E$. $e_{\lambda} \leq 0$ and $0 \leq \mathrm{e}_{\mathrm{w}} \leq 1$

This is really an innocuous assumption ${ }^{24}$ in the light of previous work; see Khan [25]. We can now state

${ }^{22}$ It is well known that $\eta_{\mathrm{i}}=-\sigma_{\mathrm{i}} / \theta_{\mathrm{iK}}$.

${ }^{23}$ This is half of Proposition 3.3. in Khan [25]. There he has also shown that $\mathrm{e}_{\lambda}<0$ and $\mathrm{e}_{\mathrm{w}} \leq 1$ imply that an equilibrium of $\mathscr{R}$ is locally, asymptotically stable.

${ }^{24}$ The only settings known to us for which $\mathrm{e}_{\mathrm{w}}$ may be greater than one are those discussed by Calvo [10;11]. However, Calvo [11] assumes a Cobb-Douglas technology in the urban sector which does imply $\mathrm{e}_{\mathrm{w}} \leq 1$. Thus the possibility $\mathrm{e}_{\mathrm{w}}>1$ rests on more general technologies. In any case, $\alpha$ sufficiently large value of $\mathrm{e}_{\mathrm{W}}$ implies instability of equilibrium in factor markets under the process discussed in Khan [23]; see footnote 23. 
PROPOSITION 4.3.1. Under Assumption E, Propositions 3.3.1 (a) and (b) are valid under intersectoral immobility of capital.

\subsection{Results on Gains from Trade in Terms of $U$}

Our first result relates to changes in the terms of trade. It is obtained by substituting (4.1.4a) in (2.9)

\section{PROPOSITION 4.4.1}

(a) Let the urban commodity be imported. Then improvements in the terms of trade improve welfare if and only if

$$
\frac{\theta_{u L^{\ell} u \eta_{u}\left(1-e_{w}\right)}}{\Delta}>\left(1-\gamma_{u}\right)
$$

(b) Let the rural commodity be imported. Then improvements in the terms of trade improve welfare if and only if

$$
\frac{\theta_{r L} \ell_{u}(1+\lambda) \eta_{r}\left(1-e_{w}\right)}{\Delta}>\left(1-\gamma_{r}\right)
$$

Remark 4.4.1. If $\mathrm{e}_{\mathrm{w}}=1$, terms of trade improvements always improve welfare.

Next, we consider the question of the existence of welfare-improving tariffs when the economy is initially in a position of laissez-faire.

PROPOSITION 4.4.2. Let $e_{\lambda} \leq 0$; factor markets by dynamically stable in terms of adjustment process $\mathscr{R}$; and let the economy be initially in a laissez-faire equilibrium. Then there exist welfare-improving tariffs if and only if ${ }^{25} e_{w}<1$.

Our final result of this sub section concerns sub-optimal tariffs and the superiority of less-restricted trade to more-restricted trade. Equations (2.6), (2.7) and (4.1.4) yield

PROPOSITION 4.4.3. Less-restricted trade is superior (inferior) to more restricted trade if and only if in the neighbourhood of $t_{i}^{*}, t_{i}>t_{i}^{*}\left(t_{i}<t_{i}^{*}\right)$, where the sub-optimal tariffs $t_{i}{ }_{i}$ are given by

$$
\begin{aligned}
\frac{t_{u}^{*}}{1+t_{u}^{*}} & =\left(\frac{1}{\gamma_{u}-1}\right)\left(\frac{1}{\epsilon_{u}}\right) \frac{\theta_{u L} \ell_{u} \eta_{u}\left(1-e_{w}\right)}{\Delta} \\
\frac{t_{r}^{*}}{1+t_{r}^{*}} & =\left(\frac{1}{\gamma_{r}-1}\right)\left(\frac{1}{\epsilon_{r}}\right) \frac{\theta_{r L} \ell_{u}(1+\lambda) \eta_{r}\left(1-e_{w}\right)}{\Delta}
\end{aligned}
$$

${ }^{25}$ It is easy to deduce from (2.4) and (4.1.4) that there exist welfare-improving tariffs if and only if $\ell_{i} \eta_{i}\left(1-e_{w}\right) / \Delta$. Since factor market stability implies, under $e_{\lambda} \leq 0$, that $\Delta>0$, Proposition 4.4.2 follows.
Remark 4.4.2. If factor markets are dynamically stable, then $t_{i}^{*}>0$ if and only if $\mathrm{e}_{\mathrm{w}}<1$.

Remark 4.4.3. If $\mathrm{e}_{\mathrm{w}}=1$, then $\mathrm{t}_{\mathrm{i}}^{*}=0$ and less-restricted trade is always superior to more restricted trade. This is an alternative statement of Proposition 4.4.2 but it does not depend on 'factor market stability. Finally, Remark 3.4 .10 is also relevant here.

\section{RELATIONSHIP WITH OTHER WORK}

Corden-Findlay [14] are the only authors to have discussed tariffs in the context of intersectoral capital mobility. Their brief discussion ${ }^{26}$ focusses on the importance of changes in the unemployment rate as the crucial determinant of the welfare-effect of tariffs. They write, "Tariffs ... may fail to raise net output at world prices because the rise in manufacturing output may be offset by a greater fall in agricultural output owing to the extra unemployment created." The results presented in this paper can be viewed as an extension and a sharpening of their basic statement. Thus in terms of the welfare function $\mathrm{W}$, trade is always beneficial when the urban commodity is being imported and never so when the rural commodity is being imported, see Proposition 3.3.1. This statement is conditioned on factor markets being dynamically stable which reduces in this context, to the requirement that the urban sector is capital intensive in employment adjusted terms; see Khan [23] and Neary [29]. In terms of the welfare function U, changes in the terms of trade are studied in Remark 3.4.2; existence of welfare-improving tariffs in Remark 3.4.7; and sub-optimal tariffs in Proposition 3.4.3. These now take the simple forms

$$
\begin{aligned}
& \frac{\mathrm{t}_{\mathrm{u}}^{*}}{1+\mathrm{t}_{\mathrm{u}}^{*}}=\left(\frac{1}{\gamma_{\mathrm{u}}-1}\right)\left(\frac{1}{\epsilon_{\mathrm{u}}}\right)\left(\frac{\mathrm{k}_{\mathrm{r}}}{\mathrm{k}_{\mathrm{u}}(1+\lambda)}\right) \\
& \frac{\mathrm{t}_{\mathrm{r}}^{*}}{1+\mathrm{t}_{\mathrm{r}}^{*}}=-\left(\frac{1}{\gamma_{\mathrm{r}}-1}\right)\left(\frac{1}{\in_{\mathrm{r}}}\right) \frac{\ell_{\mathrm{u}}(1+\lambda)}{\ell_{\mathrm{r}}}
\end{aligned}
$$

In the context of intersectorally immobile capital, Bhagwati and Srinivasan [7] "investigate optimality properties of alternative policies in regard to their effects on employment levels [in addition to] a social utility function." They observe that "a tariff policy... [is] ... equivalent to a production tax-cum-subsidy policy, plus consumption tax-cum-subsidy policy," and show that a production subsidy to the rural commodity increases employment and welfare. Furthermore, in their discussion of commercial policy in a large, open economy, Srinivasan and Bhagwati [33] present the result that ${ }^{27}$ 'A tariff (or trade subsidy) policy may not improve

\footnotetext{
${ }^{26}$ See the two paragraphs on tariffs on page 75 of their paper.

${ }^{27}$ See Theorem 9 on page 361 .
} 
welfare but can improve employment." In this paper we have limited ourselves to a small, economy and in the context of the Bhagwati-Srinivasan work, our principal contribution lies in bringing dynamic stability conditions to the fore (see Proposition 4.4.2) and in showing the sensitivity of the results to the commodity being imported. This is particularly so when urban unemployment is the sole determinant of welfare (see Proposition 4.3.1).

Hazari's [17] chapter is primarily concerned with wage subsidies but he does recognize that ${ }^{28}$ "there [may] exist trade-off possibilities between welfare and employment" and that "free trade is not the optimal policy." However, like most of the literature, Hazari is concerned with first best outcomes and does not investigate the desirability of trade in a second best setting.

Both Stiglitz and Calvo assume international prices to be unity in their papers and do not concern themselves with the issues discussed here. It should be emphasized, though, that in the context of the welfare function $\mathrm{U}$, the behaviour of Calvo's model is identical to that of the HOS or Ricardo-Viner models; see Remarks 3.4.3, 3.4.5, 3.4.8, 4.4.1 and 4.4.3. Stiglitz measures welfare net of the costs of turnover, i.e., the GNP is measured by $p_{r} X_{r}+p_{u} X_{u}-g_{q}(\lambda) L_{u}$ where $q(\lambda)$ is the quit-rate and $\mathscr{T}$ is the training-cost parameter. Since this can be rewritten as $\mathrm{p}_{\mathrm{r}} \mathrm{X}_{\mathrm{r}}+\mathrm{p}_{\mathrm{u}} \mathrm{X}_{\mathrm{u}}$ $\mathscr{I}_{\tau}(\lambda) \mathscr{U}$, we have a special case of a more general welfare function $\psi(\mathrm{U}, \mathrm{W})$. The interested reader can develop for himself an analysis of such a function using the formulae and methods developed above.

Finally, the reader can usefully compare our formulae for the sub-optimal tariffs with those developed by Kemp [20]. Kemp considers the case when the distortion is given by a tax on the production of the exported commodity.

\section{SUMMARY AND CONCLUDING REMARKS}

In 1971, H. Singer [32] wrote, "As an economist I am bound to say that the main avenue along which one would look for a major contribution to the solution of the unemployment problem in developing countries lies in trade... One cannot help being impressed by the vast potential improvement in the employment future of the developing countries which expanded trade could produce." Our Propositions 3.3.1 and 4.3.1, summarized in Table 1, formalize these statements and show their independence of urban, labour market conditions and intersectoral mobility of capital. However, the results are sensitive to the commodity being imported (fortunately, in the direction casual empiricism suggests) and to stability conditions in the factor market.

Tables 2 and 3 summarize our results pertaining to the welfare function $U$. In this case, clear-cut results are much harder to come by and labour-market conditions, $e_{w}, e_{\lambda}$ and $e_{R}$, and the relative size of the import sector, $\gamma_{r}$ and $\gamma_{u}$, play a more prominent role
Table 1

Gains from Trade in Terms of $W$

\begin{tabular}{c|c|c}
\hline \multirow{4}{*}{ Import } & $\begin{array}{c}\text { Intersectorally Mobile } \\
\text { Capital }\end{array}$ & $\begin{array}{c}\text { Intersectorally Immobile } \\
\text { Capital }\end{array}$ \\
\cline { 2 - 3 } & $(|\mathrm{D}| \mathrm{x}|\Delta|)>0$ & \\
\hline $\mathrm{r}$ & $0 \leq \mathrm{e}_{\mathrm{w}} \leq 1 ; \mathrm{e}_{\mathrm{R}} \geq 0 ; \mathrm{e}_{\lambda} \leq 0$ & $\mathrm{e}_{\lambda} \leq 0 ; 0 \leq \mathrm{e}_{\mathrm{w}} \leq 1$ \\
\hline $\mathrm{u}$ & Trade Harmful & Trade Harmful \\
\hline
\end{tabular}

Table 2

Necessary and Sufficient Conditions for Improvement in Terms of Trade to Improve $U$

\begin{tabular}{l|c|c}
\hline Import & $\begin{array}{c}\text { Intersectorally Mobile } \\
\text { Capital }\end{array}$ & $\begin{array}{c}\text { Intersectorally Immobile } \\
\text { Capital }\end{array}$ \\
\hline $\mathrm{r}$ & $\left(\mathrm{e}_{\mathrm{w}}-\mathrm{e}_{\lambda}\right)\left|\frac{\mathrm{D}}{\Delta}\right|>\frac{\mathscr{L}-\gamma_{\mathrm{r}} \mathrm{L}_{\mathrm{r}}}{\mathscr{L}-\mathrm{L}_{\mathrm{r}}}$ & $\frac{\theta_{\mathrm{rL}} \ell_{\mathrm{u}}(1+\lambda) \eta_{\mathrm{r}}\left(1-\mathrm{e}_{\mathrm{w}}\right)}{\Delta}>\left(1-\gamma_{\mathrm{r}}\right)$ \\
\hline $\mathrm{u}$ & $\left(1-\mathrm{e}_{\lambda}\right)\left|\frac{\mathrm{D}}{\Delta}\right|<\gamma_{\mathrm{u}}$ & $\frac{\theta_{\mathrm{uL}} \mathrm{l}_{\mathrm{u}} \eta_{\mathrm{u}}\left(1-\mathrm{e}_{\mathrm{w}}\right)}{\Delta}>\left(1-\gamma_{\mathrm{u}}\right)$ \\
\hline
\end{tabular}

We have not investigated the questions of gains from trade when the sufficient conditions in Propositions 3.3.1 and 4.3.1 do not hold. It should be a simple but tedious matter to provide a more complete taxonomy using our formulae and methods. It is doubtful whether this would add any further insight.

In conclusion, it is worth reiterating that the generalized Harris-Todaro model is of interest primarily because by analyzing it, we analyze several models all at once. It enables one to study a variety of labour market conditions all under one roof, so to speak. However, a synthesis can be pushed too far and there does come a point beyond which the economics of the different settings call for separate analyses. This 
Table 3

Necessary and Sufficient Conditions for the Existence of a U-improving Tariff from an Initial Position of Laissez-Faire

\begin{tabular}{c|c|c}
\hline Import & $\begin{array}{c}\text { Intersectorally Mobile } \\
\text { Capital }\end{array}$ & $\begin{array}{c}\text { Intersectorally Immobile } \\
\text { Capital }\end{array}$ \\
\hline $\mathrm{r}$ & $\left(\mathrm{e}_{\mathrm{w}}-\mathrm{e}_{\lambda}\right)\left|\frac{\mathrm{D}}{\Delta}\right|<1$ & \\
\hline $\mathrm{u}$ & $\left(1-\mathrm{e}_{\lambda}\right)\left|\frac{\mathrm{D}}{\Delta}\right|>1$ & $\mathrm{e}_{\mathrm{w}}<1$ if $\Delta>0$ \\
\hline
\end{tabular}

is particularly so for normative questions where the choice of the objective is of importance. However, it is also worth stressing that the model can be studied in its own right rather than as a synthesis and with qualitative information on its crucial parameters $\mathrm{e}_{\lambda}, \mathrm{e}_{\mathrm{w}}$ and $\mathrm{e}_{\mathrm{R}}$ obtained from a straight-forward econometric estimation of the urban wage equation. In either case it is our hope that the results of this paper show that the analysis of the generalized Harris-Todaro model in the context of sub-optimal tariff policy does yield a position return.

\section{REFERENCES}

1. Akerlof, G., and J. Stiglitz. "Capital, Wages and Structural Unemployment”. Economic Journal. 1969. pp. 269-81.

2. Batra, R. N. Studies in the Pure Theory of International Trade. London: The Macmillan Press. 1973.

3. Bhagwati, J. "The Generalized Theory of Distortions and Welfare". In Trade Balance of Payments and Growth. J. N. Bhagwati, et al., (eds.), Amsterdam: North-Holland Publishing Company. 1971.

4. Bhagwati, J. "The Theory of Immiserising Growth: Further Applications". In M. B. Connolly and A.K. Swoboda (eds.), International Trade and Money. Toronto: University of Toronto Press. 1973.

5. Bhagwati, J., and Murray Kemp. "Ranking of Tariffs Under Monopoly Power in Trade". Quarterly Journal of Economics. Vol. 83. 1969. pp. 331-35.

6. Bhagwati, J., V. K. Ramaswami and T.N. Srinivasan. "Domestic Distortions, Tariffs and the Theory of Optimum Subsidy: Some Further Results". Journal of Political Economy. Vol. 77. 1969. pp. 1005-10.
7. Bhagwati, J., and T. N. Srinivasan. "On Reanalyzing the Harris-Todaro Model: Policy Rankings in the Case of Sector-Specific Sticky Wages". American Economic Review. 1974. pp. 502-08.

. "The Ranking of Policy Interventions Under Factor Market Imperfections: the Case of Sector-Specific Sticky Wages and Unemployment". Sankhya. Series B. 1973.

9. Brecher, R. A. "Optimal Commercial Policy for a Minimum Wage Economy". Journal of International Economics. Vol. 4. 1974. pp. 139-49.

10. Calvo, Guillermo A. "Quasi-Walrasian Theories of Unemployment". American Economic Review. Vol. 69. 1979. pp. 102-07.

11. Calvo, Guillermo A. "Urban Unemployment and Wage Determination in LDC's: Trade Unions in the Harris-Todaro Model". International Economic Review. Vol. 19. 1978. pp. 65-81.

12. Caves, R. E., and R.W. Jones. World Trade and Payments. Boston: Little, Brown and Company. 1973.

13. Corden, W. M. Trade Policy and Economic Welfare. Oxford, England: Oxford University Press. 1974.

14. Corden, W. M., and R. Findlay. "Urban Unemployment, Intersectoral Capita Mobility and Development Policy". Economica. Vol. XLII. 1975 pp. 59-78.

15. Gorman, W. M. "Tricks with Utility Functions". In M. Artis and A. Nobay (eds.), Essays in Economic Analysis. Cambridge: Cambridge University Press. 1976.

16. Harris, J. R., and M. Todaro. "Migration, Unemployment and Development: A Two Sector Analysis". American Economic Review. Vol. LX. 1970. pp. $126-42$.

17. Hazari, B. A. The Pure Theory of International Trade and Distortions. New York: John Willey and Sons. 1978.

18. Jones, R. W. "Distortions in Factor Markets and the General Equilibrium Model of Production". Journal of Political Economy. Vol. 79. 1971. pp. 437-59.

19. Jones, R. W. "Income Distribution and Effective Protection in a Multicommodity Trade Model". Journal of Economic Theory. Vol. 14. 1975. pp. 337-48.

20. Kemp, Murray C. The Pure Theory of International Trade and Investment. Englewood Cliffs, N. J.: Prentice Hall. 1969.

21. Kemp, Murray C. "Some Issues in the Analysis of Trade Gains". Oxford Economic Papers. Vol. 20. 1968. pp. 149-61.

22. Kemp, Murray C., and T. Negishi. "Domestic Distortions, Tariffs and the Theory of the Optimum Subsidy". Journal of Political Economy. Vol. 77. 1969. pp. $1011-13$. 
23. Khan, M. Ali. "Dynamic Stability, Wage Subsidies and the Generalized HarrisTodaro Model”. Pakistan Development Review. Vol. XIX. 1980. pp. 1-24.

24. Khan, M. Ali. "The Harris-Todaro Hypothesis and the Heckscher-OhlinSamuelson Trade Model: A Synthesis". Journal of International Economics. Vol. X. 1980. pp. 527-47.

25. Khan, M. Ali. "A Multisectoral Model of a Small, Open Economy with NonShiftable Capital and Imperfect Labor Mobility". Economics Letters. Vol. II. 1979. pp. 369-75.

26. Khan, M. Ali. "Social Opportunity Costs and Immiserizing Growth: Some Observations on the Long Run Versus the Short". Quarterly Journal of Economics. Vol. XCVII. 1982. pp. 353-362.

27. Krueger, A. O., and H. Sonnenschein. "The Terms of Trade, the Gains from Trade and Price Divergence". International Economic Review. Vol. 8. 1967. pp. 121-27.

28. Neary, J. Peter. "Dynamic Stability and the Theory of Factor-Market Distortions". American Economic Review. Vol. 68. 1978. pp. 672-82.

29. Neary, J. Peter. "On the Harris-Todaro Model with Intersectoral Capital Mobility”. Economica. Vol. 48. 1981. pp. 219-234.

30. Sabot, R. H. (ed.). Migration and the Labor Market in Developing Countries. Boulder, Co.: The Westview Press. 1982.

31. Samuelson, P. A. "The Gain from International Trade". Canadian Journal of Economics and Political Science. Vol. 5. 1939. pp. 195-205.

32. Singer, H. W. "International Policy and its Effect on Unemployment". In R. Robinson and P. Johnson (eds.), Prospects for Employment Opportunities in the Nineteen Seventies. London: HMSO. 1971.

33. Srinivasan, T. N. and J. Bhagwati. "Alternative Policy Rankings in a Large, Open Economy with Sector-Specific, Minimum Wages". Journal of Economic Theory. Vol. 11. 1975. pp. 356-71.

34. Stiglitz, J. E. “Alternative Theories of Wage Determintion and Unemployment in LDC's: The Labor-Turnover Model". Quarterly Journal of Economics. Vol. LXXXVIII. 1974. pp. 194-227.

35. Stiglitz, J. E. "The Efficiency Wage Hypothesis, Surplus Labor, and the Distribution of Income in LDC's". Oxford Economic Papers. Vol. XXVIII. 1976. pp. 185-207.

36. Stiglitz, J. E. “The Structure of Labor Markets and Shadow Prices in LDC's". In R. H. Sabot (ed.), Migration and the Labor Market in Developing Countries. Boulder, Co.: The Westview Press. 1982. (Proceedings of a Conference held by the World Bank, May 1978) 